Terbit online pada laman web jurnal: http://jurnal.iaii.or.id

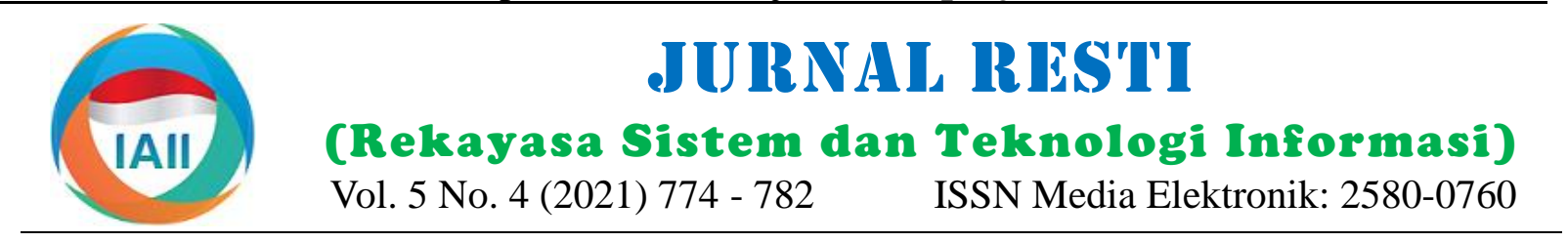

\title{
Simulator Proses Pengisian dan Pemasangan Tutup Botol Terkendali PLC Berbantuan Miniatur Konveyor
}

\author{
Anang Dwi Purnomo ${ }^{1}$, Arief Goeritno ${ }^{2 *}$, Danang Adi Nugroho ${ }^{3}$ \\ ${ }^{1}$ Laboratorium Instrumentasi dan Otomasi, Universitas Ibn Khaldun Bogor \\ ${ }^{2}$ Program Studi Teknik Elektro, Fakultas Teknik dan Sains, Universitas Ibn Khaldun Bogor, \\ ${ }^{3}$ PT Serena Indopangan Industri, Kelurahan Cibinong, Kecamatan Cibinong, Kabupaten Bogor. \\ ${ }^{1}$ anangdwipurnomo.ad@gmail.com, ${ }^{2}$ arief.goeritno@uika-bogor.ac.id*,33 danang421.10@gmail.com
}

\begin{abstract}
A miniature conveyor machine assisted by embedded systems and controlled by a programmable logic controller (PLC) has been fabricated with the operating mechanism is based on the detection of two different colors. The objectives of this research are to obtain a miniature machine is controlled by the PLC system, create a ladder diagram-based program structure, and measure the performance of the embedded system. Obtaining the machine is carried out through assembly of the conveyor frame, installation of all devices, and integrated wiring. The programming for the Omron PLC system is based on providing the CX-Programmer 64 bits, establishing algorithms and compiling ladder diagrams, and compiling and uploading processes. The performance measurement includes synchronization conditions between the simulator and the control system, observations of the readings of installed sensors for activating all devices on the output side, and observing the measurement of the filling process time and the installation of bottle caps assisted by the pneumatic system. The results of the performance during the process of filling and installing the lid obtained a success rate of 75\%, based on four trials, three successes, and one failure. The general conclusion is that the embedded system that has been built can be used as a simulator for the mechanism of filling liquid into bottles and installing bottle caps, and it is as an implementation of instrumentation and automation processes.
\end{abstract}

Keywords: A miniature of the conveyor machine, embedded system, programmable logic controller system, simulator for the process of filling and installing bottle caps.

\begin{abstract}
Abstrak
Telah dihasilkan sebuah miniatur mesin konveyor berbantuan sistem tertanam terkendali oleh programmable logic controller (PLC) dengan mekanisme operasi mesin berdasarkan kepada deteksi terhadap dua warna berbeda. Tujuan penelitian ini berupa memperoleh sebuah miniatur mesin terkendali oleh sistem $P L C$, membuat struktur program berbasis ladder diagram, dan mengukur kinerja sistem tertanam. Perolehan mesin dilakukan melalui perakitan kerangka konveyor, pemasangan seluruh perangkat, dan pengawatan terintegrasi. Metode pemrograman terhadap sistem PLC Omron didasarkan kepada penyediaan CX Programmer 64 bit, penetapan algoritma dan penyusunan ladder diagram, dan proses compiling dan uploading. Pengukuran kinerja meliputi kondisi sinkronisasi antara simulator dan sistem kontrol, pengamatan terhadap pembacaan sensor-sensor terpasang untuk pengaktifan seluruh perangkat di sisi keluaran, dan pengamatan terhadap pengukuran waktu proses pengisian dan pemasangan tutup botol berbantuan sistem pneumatic. Hasil kinerja saat proses pengisian dan pemasangan tutup diperoleh tingkat keberhasilan sebesar 75\%, berdasarkan empat kali uji coba, tiga kali berhasil dan satu kali gagal. Kesimpulan secara umum, bahwa sistem tertanam yang telah dibangun dapat digunakan sebagai simulator untuk mekanisme pengisian cairan ke dalam botol dan pemasangan tutup botol, dan hal itu sebagai implementasi terhadap instrumentasi dan proses otomasi.
\end{abstract}

Kata kunci: Miniatur mesin konveyor, sistem tertanam, sistem pengontrol logika terprogram, proses pengisian dan pemasangan tutup botol.

\section{Pendahuluan}

Salah satu produk alat pengisian air minum ke dalam botol berbasis pengontrol logika terprogram atau PLC yang tersedia di pasaran dengan merek dagang Omron dengan tipe CP1E-E20SDR-A telah diwujudkan [1]. Alat pengisian berbasis sistem otomasi tersebut berpedoman kepada konsepsi "beverage filling system" [2], yaitu perwujudan sebuah sistem tertanam (embedded system) yang berbasis PLC [3-9]. Penggunaan PLC OMRON tipe CP1E [10] pada prototipe yang telah terpabrikasi $[11,1,12]$, maupun pemakaian $P L C$ dengan merek lainnya [13] sebagai alat

Diterima Redaksi: 05-06-2021 | Selesai Revisi: 22-08-2021 | Diterbitkan Online: 25-08-2021 
pengontrol pada sejumlah hasil penelitian [14-16] pun Komputer solid-state untuk keperluan industri [3-9] telah menjadi suatu keniscayaan. Sisi masukan (input) merupakan inti dari PLC dalam pemantauan terhadap pada PLC Omron tipe CP1E-E20SDR-A untuk jalur masukan-keluaran dan pembuatan keputusan terhubung dengan photoelectric sensor dan push button, berbasis logika dalam suatu proses otomatisasi [3-9, 22]. sedangkan sisi keluaran (output) terhubung ke aktuator Keberadaan PLC sejak ditemukan pada tahun 1968, untuk pengoperasian motor $d c$ dan solenoid valve [1]. lebih sebagai evolusi teknologi daripada penemuan yang Hasil penelitian dari Chaerunnisa dan kawan-kawan [1] spektakuler, sehingga PLC telah menjadi pemeran merupakan bentuk metode untuk identifikasi sistem penting dalam operasi manufaktur sejak saat itu [3-9]. pengisian air minum secara otomatis. Peran utama PLC Pemanfaatan teknologi PLC yang telah ada selama dilengkapi dengan cara pemilihan untuk jalur (port) beberapa waktu terakhir, sehingga keberadaan $P L C$ input dan output terpakai dan pembuatan ladder diagram masih menjadi bagian penting dalam industri hingga saat pada program $C X$-programmer merupakan suatu pilihan ini [3-9]. Diagram blok sistem PLC [13] untuk sesuai kebutuhan [1,12]. Identifikasi pada sistem berupa pengendalian, pengontrolan, dan otomasi, seperti tanda high dari $P L C$ berupa angka 1 sebagai penanda $I / O$ ditunjukkan pada Gambar 1.

(input/output) aktif dan low berupa angka 0 sebagai penanda $I / O$ tidak aktif sesuai program [1]. Operasi sistem dapat diketahui dengan baik dari indikator tersebut. Time base digunakan sebagai batas ukur waktu pengisian cairan ke dalam botol [1].

Penelitian lain berkaitan dengan sistem pengisian cairan ke dalam botol secara otomatis [11], dilakukan melalui pemanfaatan PLC merek Omron tipe CP1E [2] untuk pengemasan susu dalam botol terhadap purwarupa filling bottle and capping machine [11]. Pemanfaatan $P L C$ pada sistem tersebut difungsikan sebagai pengontrol proses pengisian cairan ke dalam botol. Implementasi sistem filling bottle and capping machine [11] merupakan salah satu bentuk otomasi permesinan di bidang industri $[17,18]$. Pemanfaatan $P L C$ juga digunakan untuk pengontrolan pada pengoperasian mesin konveyor melalui proses penggerakan botol [11, 12]. Penggerakan mesin konveyor dilakukan dengan bantuan motor direct current $(d c)$ [11, 12, 15, 16]. Keberadaan sistem tertanam berbasis $P L C$ di dunia industri dengan kemampuan operasi cepat dan akurat telah menjadi pilihan, agar diperoleh peningkatan kuantitas maupun kualitas hasil produksi [19-21].

Tugas utama $P L C$ dalam pembuatan inventarisasi kesalahan, digunakan untuk perbaikan terhadap kesalahan tersebut melalui permulaan program pada sistem pengisian. Pembuatan dan pemberian instruksi pada tahapan lanjutan dengan posisi yang telah diprogram sebelumnya dan/atau tindakan lain $[17,18$, 20] merupakan tugas utama lain dari $P L C$. Berdasarkan hal itu, maka $P L C$ beroperasi dalam pembuatan dan pemeliharaan riwayat kesalahan yang terdeteksi untuk setiap posisi pengisian secara real time $[17,18,20]$, agar dimungkinkan deteksi dan koreksi langsung terhadap posisi pengisi yang rusak secara langsung [17-21]. Keberadaan sejumlah sensor tersambung di jalur (port) masukan, sedangkan pada port keluaran (output) difungsikan untuk pengaktifan sejumlah aktuator dalam integrasi sebuah sistem otomasi berbasis komputer personal (personal computer, PC) [22] atau PLC pada umumnya [3-9], atau modul mikrokontroler telah menjadi suatu keniscayaan [23-29].

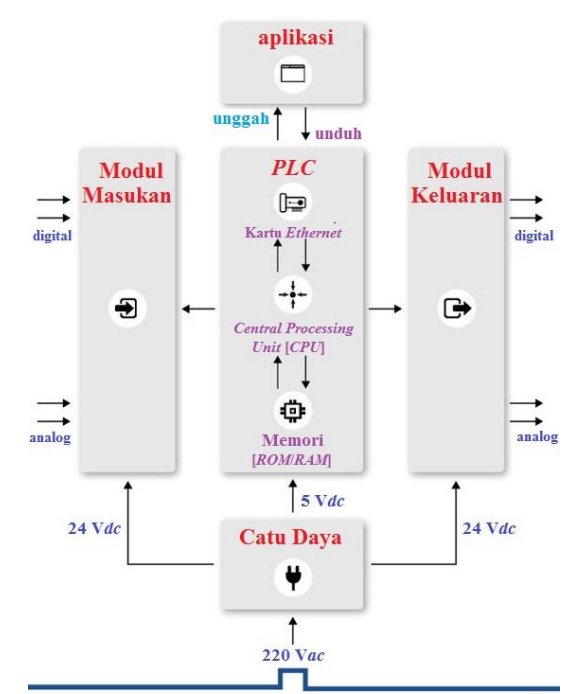

Gambar 1. Diagram blok sistem PLC untuk pengendalian, pengontrolan, dan otomasi

Berdasarkan sejumlah hasil penelitian terdahulu ditunjukkan, bahwa prototipe sistem berbasis PLC OMRON tipe CP1E-E20SDR-A [1] telah digunakan untuk sistem otomasi pengisian air minum, sedangkan sistem pengisian berbasis mikrokontroler [23-29] telah digunakan sebagai aplikasi pada alat pengisian air minum dan penutup botol. Berdasarkan hal itu, maka dilakukan pabrikasi sebuah embedded system berbasis PLC Omron CP1E-E30SDR-A untuk mesin simulator proses pengisian air minuman ke dalam botol dan mekanisme pemasangan tutup botol. Pengisian dan pemasangan dilakukan secara otomatis dengan sistem pengisian yang didasarkan kepada warna botol, kemudian botol yang telah terisi air dipindahkan oleh miniatur konveyor setelah pemberian penutup secara otomatis. Rumusan masalah pada penelitian ini dibuat dalam bentuk diagram blok. Diagram blok rumusan masalah, seperti ditunjukkan pada Gambar 2.

Berdasarkan Gambar 2 dapat dijelaskan, bahwa pada port masukan PLC terhubung dengan push button, selector switch, RGB fiberoptic sensor, dan photoelectric sensor, sedangkan pada port keluaran PLC 
terhubung dengan pneumatic valve, motor $d c$, dan ducting, kotak panel, push button, selector switch, kabel pompa pada tangki.

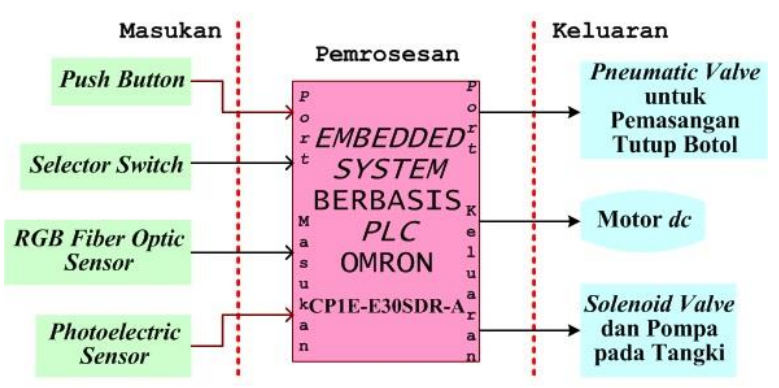

Gambar 2 Diagram blok rumusan masalah

Mekanisme pengoperasian embedded system melalui sejumlah tahapan, yaitu (i) saat botol berwarna merah/hijau terdeteksi oleh photoelectric sensor, maka pompa tangki-1/tangki-2 beroperasi untuk pengisian cairan "rasa strawberry"/"rasa lemon" pada botol berdasarkan penyetelan waktu dan (ii) setelah proses pengisian selesai, maka sistem penutup botol beroperasi untuk penutupan botol. Sketsa tampilan embedded system berbasis $P L C$ untuk simulator proses pengisian air ke dalam botol dan pemasangan tutup botol, seperti ditunjukkan pada Gambar 3.

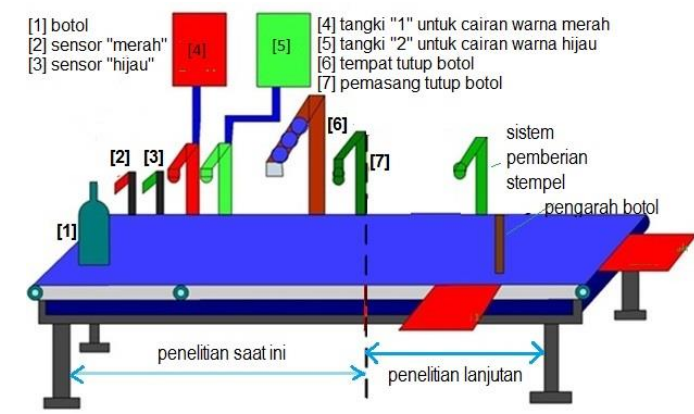

Gambar 3. Tampilan sketsa embedded system berbasis $P L C$ untuk simulator proses pengisian ke dalam botol dan pemasangan tutup botol

Berpedoman kepada mekanisme tersebut sketsa embedded system, maka penelitian ini dengan sasaran penelitian berupa (a) membuat dan merakit sebuah miniatur mesin sebagai simulator sistem mekanis berbasis embedded system untuk mekanisme pengisian air minuman dalam kemasan botol berdasarkan deteksi terhadap dua warna dan pemberian tutup botol secara otomatis, (b) membuat struktur program berbasis ladder diagram untuk sistem $P L C$, dan (3) mengukur kinerja embedded system berbasis PLC.

\section{Metode Penelitian}

Sejumlah peranti elektronika dan bahan peneliti diperlukan pada penelitian ini. Sebuah PLC merek Omron tipe CP1E-E30SDR-A, belt conveyor, motor $d c$, sensor photoelectric, pompa air mini, water solenoid valve, relay dan socket merek Omron tipe MY4N, MCB, switch mode power supply (SMPS), din rail, cable jenis NYAF, dan sepatu kabel. Tahapan-tahapan pada metode penelitian dibuat dalam bentuk diagram alir (flowchart). Diagram alir metode penelitian, seperti ditunjukkan pada Gambar 4.

Berdasarkan Gambar 4 dapat dijelaskan, bahwa penelitian ini terdiri atas tiga sasaran penelitian. Perolehan awal berupa bentuk fisis embedded system berbasis $P L C$ untuk pengoperasian sistem mekanis pengisian cairan ke dalam botol dan pemberian tutup pada botol secara otomatis. Wujud rancang-bangun berbentuk bangunan fisis berbasis sistem tertanam untuk sistem mekanis, dilakukan melalui (i) tahapan pembuatan miniatur mesin konveyor, (ii) penempatan sensor-sensor, (iii) pemasangan silinder pneumatic dan pompa, dan (iii) pembuatan panel operasi, penempatan komponen, dan pengawatan (wiring) sistem terintegrasi.

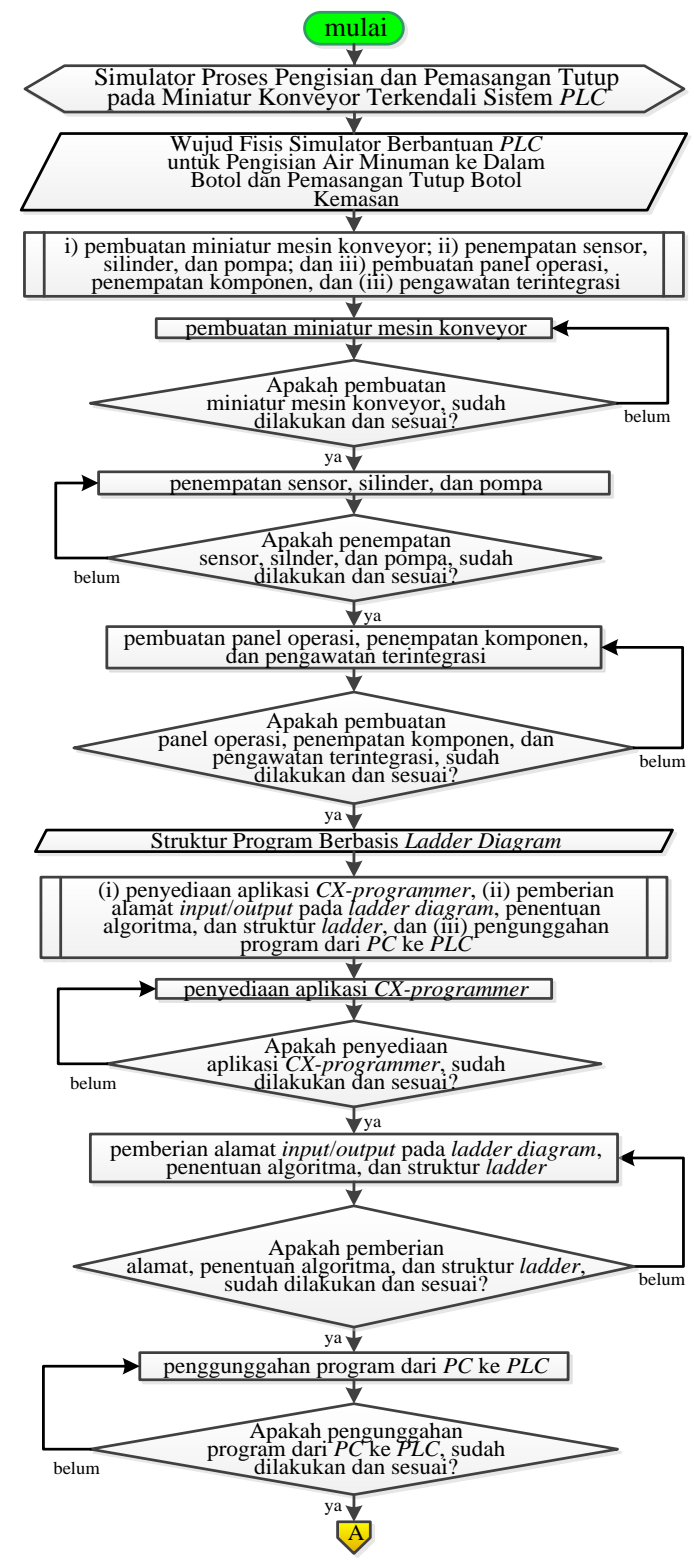

DOI: https://doi.org/10.29207/resti.v5i4.3189

Lisensi: Creative Commons Attribution 4.0 International (CC BY 4.0) 


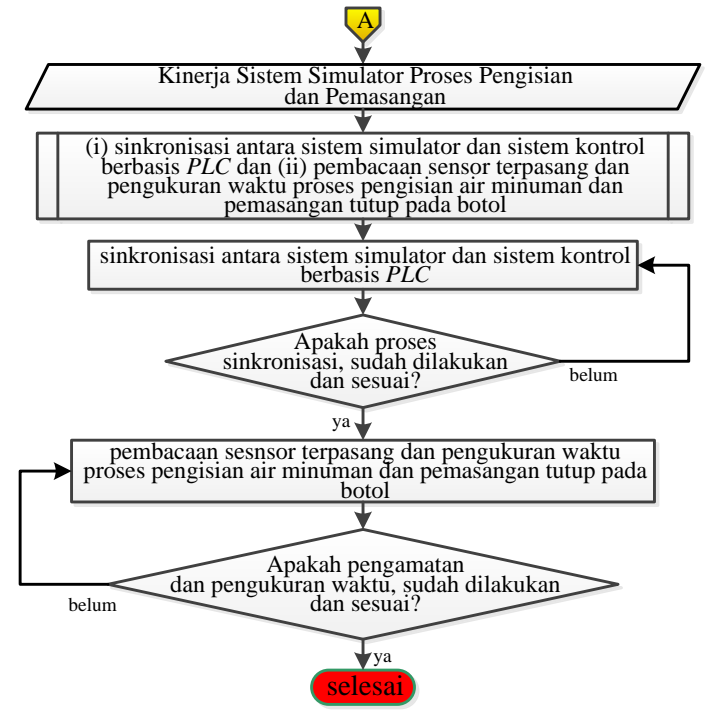

Gambar 4. Diagram alir metode penelitian

Pembuatan struktur program berbasis ladder diagram, dilakukan melalui (i) penyediaan aplikasi $C X$ programmer, (ii) pemberian alamat pada input/output pada ladder diagram, penentuan algoritma, dan struktur ladder, dan (iii) penggunggahan struktur program dari $P C$ ke $P L C$. Pengukuran kinerja sistem simulator, dilakukan melalui langkah-langkah (i) pengamatan saat sinkronisasi antara sistem simulator dan sistem kontrol untuk pengisian air minuman ke dalam botol dan pemasangan tutup pada botol setelah proses pengisian, (ii) pengamatan terhadap pembacaan sensor-sensor terpasang, dan (iii) pengamatan dan pengukuran waktu proses pengisian air minuman ke dalam botol dan pemasangan tutup pada botol

\section{Hasil dan Pembahasan}

3.1. Simulator untuk Pengisian Air dan Pemasangan Tutup Botol

Pembuatan perangkat untuk sistem pengisian air minuman ke dalam botol dan pemasangan tutup botol kemasan berbantuan $P L C$, dilakukan dengan tahapantahapan i) pembuatan miniatur mesin konveyor, ii) penempatan sensor dan sistem pneumatic, dan iii) pengawatan terintegrasi sistem. Diagram skematis perwujudan fisis simulator, seperti ditunjukkan pada Gambar 5.

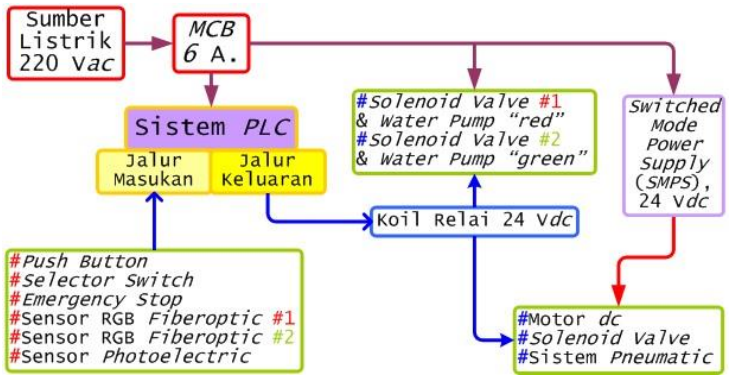

Gambar 5. Diagram skematis perwujudan fisis simulator
Berdasarkan Gambar 5 ditunjukkan, bahwa tegangan masukan $220 \mathrm{Vac}$ disambungkan pada terminal power pada PLC dan switched mode power supply $24 \mathrm{Vdc}$ melalui miniature circuit breaker $(M C B) 6$ ampere sebagai sistem proteksi terhadap sistem simulator. Tegangan operasi sistem kendali $24 \mathrm{~V} d c$ untuk pengoperasian simulator, agar lebih aman bagi komponen kontrol dan operator dalam pengoperasian.

\subsection{1) Miniatur mesin konveyor dan penempatan} perangkat

Miniatur mesin konveyor menjadi media penggerak botol pada simulator ini. Miniatur mesin konveyor berukuran $200 \mathrm{~cm}$ x $10 \mathrm{~cm}$, meliputi bagian-bagian (i) kerangka konveyor (ii) plat $2 \mathrm{~mm}$ digunakan sebagai dudukan konveyor, (iii) roller pada konveyor berdiameter $5 \mathrm{~cm}$ dan panjang $15 \mathrm{~cm}$ dilengkapi shaft coupling untuk sambungan ke poros motor $d c$, (iv) guide digunakan sebagai pengaman botol, agar tidak terjatuh pada saat bergerak pada konveyor. Wujud miniatur mesin konveyor, seperti ditunjukkan pada Gambar 6.

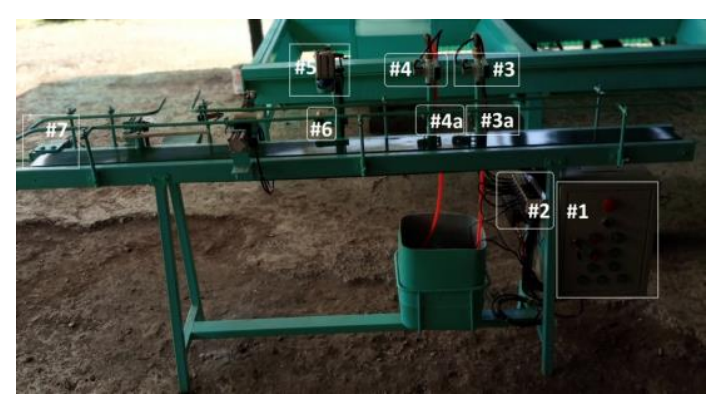

Keterangan pada gambar:

\#1 Panel Pengoperasian

\#2 Solenoid Valve sebagai Aktuator untuk Cylinder Pneumatic \#3 Solenoid Valve dan Water Pump untuk Cairan Warna Merah \#3a Sensor RGB Fiberoptic untuk Cairan Warna Merah \#4 Solenoid Valve dan Water Pump untuk Cairan Warna Hijau \#4a Sensor RGB Fiberoptic untuk Cairan Warna Hijau \#5 Cylinder Pneumatic untuk Pemasangan Tutup Botol \#6 Sensor Photoelectric untuk untuk Pemasangan Tutup Botol \#7 Motor $d c$ untuk Penggerak Belt Conveyor

Gambar 6. Wujud miniatur mesin konveyor

Berdasarkan Gambar 6 ditunjukkan, bahwa belt untuk mesin konveyor terbuat dari bahan PVC berukuran 200 $\mathrm{cm} \times 10 \mathrm{~cm}$. Motor penggerak berupa motor $d c$ dengan sistem tegangan 24 volt. Bentuk fisis motor $d c$ penggerak miniatur mesin konveyor, seperti ditunjukkan pada Gambar 7 .

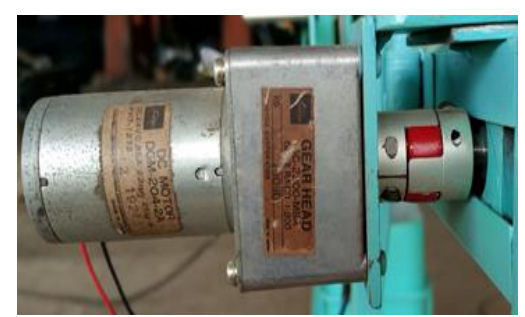

Gambar 7. Bentuk fisis motor $d c$ penggerak miniatur mesin konveyor

DOI: https://doi.org/10.29207/resti.v5i4.3189

Lisensi: Creative Commons Attribution 4.0 International (CC BY 4.0) 
Berdasarkan Gambar 7 ditunjukkan, bahwa pengaturan terminal pada auxiliary contact untuk (i) motor $24 \mathrm{Vdc}$ kecepatan putar dengan rasio 1:200 berkecepatan 22 (CR 100.00), (ii) "red" dan "green" water pump dan revolutions per minute (RPM) dan telah dilengkapi solenoid valve (CR 100.01 dan CR 100.02), (iii) untuk dengan shaft coupling.

3.1.2) Panel, penempatan komponen, dan pengawatan terintegrasi sistem kendali berbasis $P L C$

Kotak panel pengoperasian berukuran 30 × 40 × $18 \mathrm{~cm}$ untuk penempatan komponen-komponen dan dilakukan pengintegrasian pengawatan. Penampang fisis kotak panel dan terminal-terminal penghubung komponenkomponen, seperti ditunjukkan pada Gambar 8.

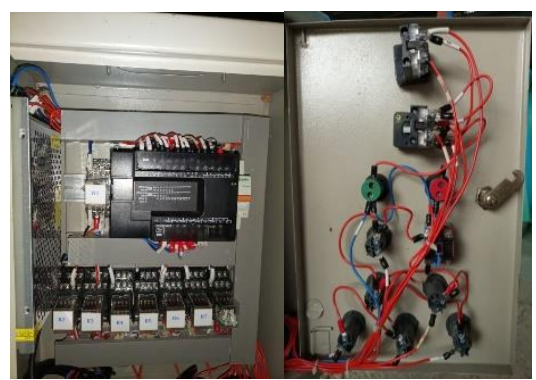

Gamabr 8 Penampang fisis kotak panel dan terminalterminal penghubung komponen-komponen

Berdasarkan Gambar 8 ditunjukkan, bahwa tata letak komponen disesuaikan dengan ketersediaan tempat. Masukan (input) dan keluaran (output) pada PLC digunakan kabel warna merah beroperasi dengan tegangan $24 \mathrm{Vdc}$ ditandai pemberian sepatu kabel berbeda untuk kutub positif dan negatif.

Keluaran dari catu daya 220 Vac untuk keperluan pasokan ke solenoid valve, water pump, dan sistem PLC. Tegangan keluaran dari switched mode power supply dan keluaran $P L C$ dihubungkan ke koil relai elektromekanik untuk tegangan operasi. Penggunaan relai bertujuan untuk pengamanan terhadap contact point pada output PLC, sehingga contact point pada output PLC tidak terbebani lebih dari kemampuan. Fungsi relai elekromekanik sebagai penghubung atau pemutus operasi aktuator, untuk keperluan (i) motor 24 $\mathrm{V} d c$ untuk mesin konveyor, (ii) solenoid valve $24 \mathrm{Vdc}$ untuk sistem pneumatic, (iii) motor $220 \mathrm{Vac}$ untuk pompa air, (iii) water solenoid valve $220 \mathrm{Vac}$. Merek Omron tipe MY4N pada relai elektromekanik disesuaikan dengan keberadaan merek $P L C$.

Penggunaan pada port masukan PLC berjumlah 12 masukan untuk keperluan (i) tombol tekan (push button), (ii) tombol tekan emergency stop, (iii) selector switch, (iv) sensor photoelectric, dan (v) sensor RGB fiberoptic. Tipe masukan pada port masukan di PLC berupa tipe negatif $24 \mathrm{Vdc}$ dan sensor bertipe NPN (Negative Positive Negatve), sedangkan terminal commonly (com) pada port masukan diberi kutub positif. Relai elektromekanik terhubung ke port keluaran PLC sebanyak 5 (lima) buah yang digunakan untuk keperluan sistem pengisian dan pemasangan tutup botol, melalui solenoid valve pemasangan tutup botol (CR 100.03), dan (iv) solenoid valve pada mekanisme pressing terhadap tutup botol (CR 100.04).

Diagram pengawatan keterhubungan pada port masukan dan keluaran, seperti ditunjukkan pada Gambar 9.
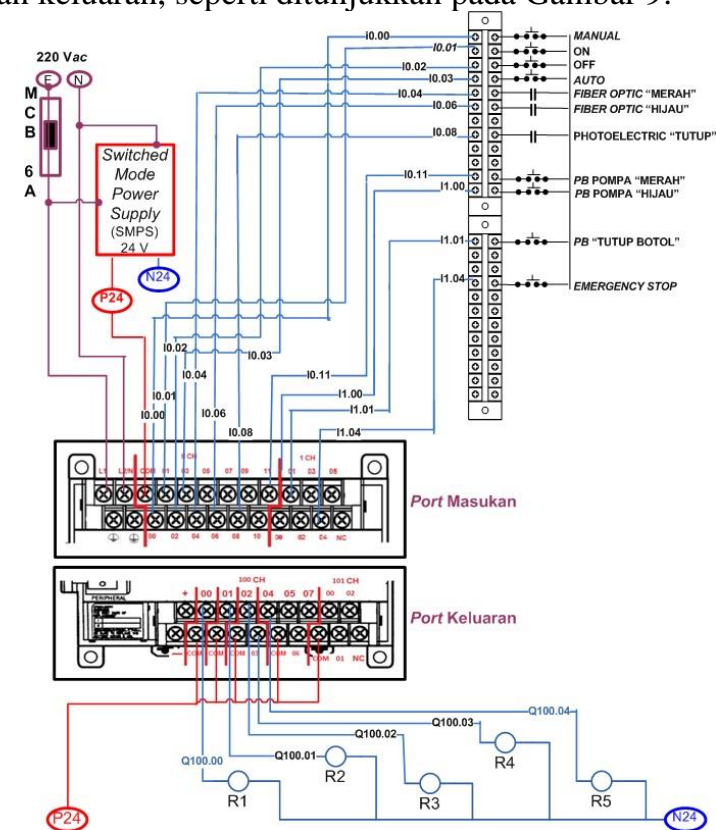

\#a) keterhubungan komponen-komponen pada port masukan

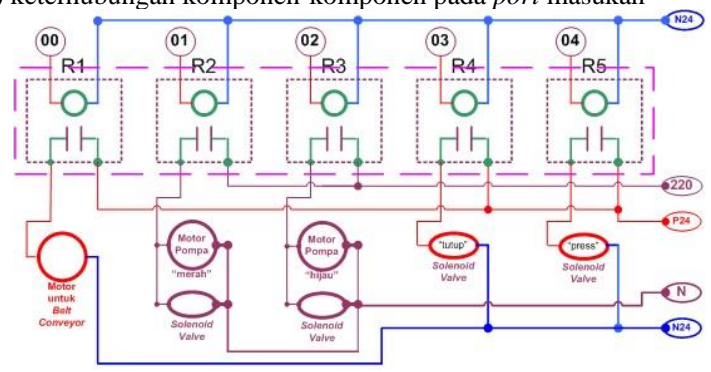

\#b) keterhubungan komponen-komponen pada port keluaran

Gambar 9. Diagram pengawatan keterhubungan pada masukan dan keluaran

\subsection{Pemrograman Berbasis Ladder Diagram}

Sejumlah tahapan untuk pembuatan struktur program berbasis ladder diagram, yaitu (i) penyediaan aplikasi CX-programmer, (ii) pemberian alamat input/output pada ladder diagram, penentuan algoritma, dan struktur ladder, dan (iii) penggunggahan struktur program dari $P C$ ke $P L C$.

\subsubsection{Penyediaan aplikasi $C X$-programmer}

$C X$-programmer merupakan sebuah aplikasi yang digunakan sebagai media pemrograman PLC dengan merek dagang Omron. Tahapan pada proses pemasangan aplikasi $C X$-programmer, berupa (i) proses penyalinan aplikasi pada komputer, dari folder $C X-O N E$ ke Data di 
drive D komputer dan (ii) proses pemasangan (peng- algoritma pemrograman terhadap sistem pengisian dan install-an) dengan tahapan buka folder $C X-O N E$ yang pemasangan tutup botol, seperti ditunjukkan pada telah disalin pada Data D, (ii) klik 2 kali pada product Gambar 11.

setup, (iii) pilih bahasa yang diinginkan, (iv) klik Yes pada setiap permintaan peng-install-an, dan (v) klik finish, jika proses peng-install-an sudah selesai. Tampilan aplikasi $C X$-programmer pada saat pertama kali dibuka, seperti ditunjukkan pada Gambar 10.

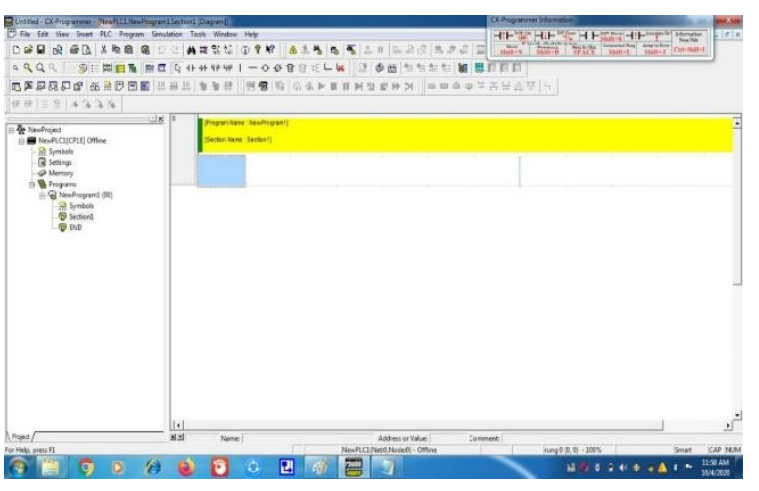

Gambar 10. Tampilan aplikasi $C X$-programmer pada saat pertama kali dibuka
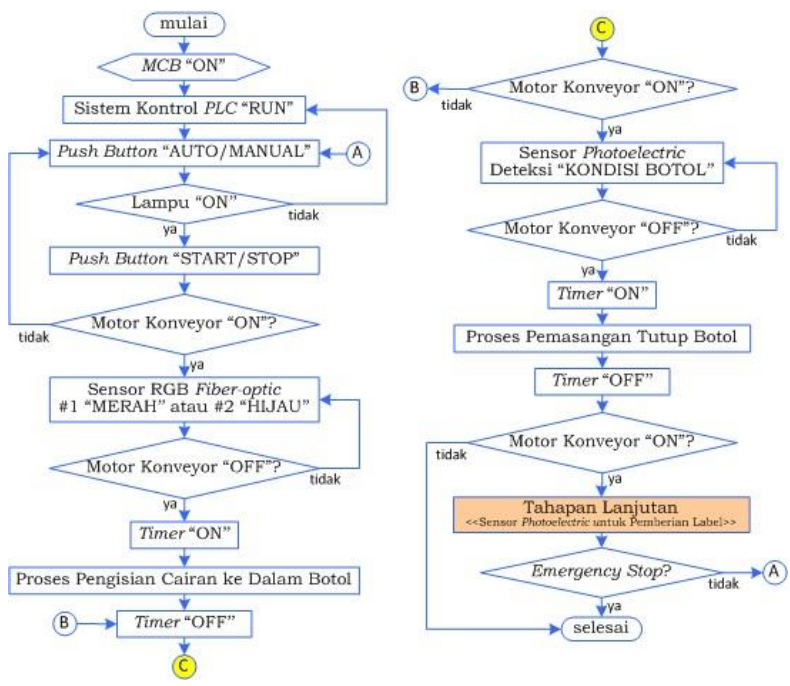

Gambar 11. Tahapan-tahapan pada algoritma pemrograman sistem pengisian dan pemasangan tutup botol

Berdasarkan Gambar 10 ditunjukkan, bahwa harus Berdasarkan Gambar 11, maka dilakukan penyusunan dilakukan pemilihan tipe $P L C$ dan kabel komunikasi struktur ladder untuk pemrograman PLC. Salah satu yang digunakan untuk penggunaan apliasi ini. Pemilihan tampilan susunan ladder, seperti ditunjukkan pada tipe $P L C$ berpengaruh pada fitur perintah yang terdapat Gambar 12. pada $C X$-programmer.

3.2.2. Pemberian alamat input/output pada ladder diagram, penentuan algoritma, dan struktur ladder

Pemrograman sistem $P L C$ didasarkan pada pemberian alamat pada port masukan/keluaran, penetapan alogaritma, dan pembuatan struktur ladder dengan $C X$ programmer. Pengalamatan input dan output pada Setelah penentuan algoritma dan penyusunan struktur sistem PLC harus ditentukan untuk kemudahan dalam ladder, kemudian dilakukan proses compiling dan proses pemrograman dan pengawatan. Penetapan alamat uploading dari PC ke dalam PLC berbantuan kabel USB. pada jalur input dan output, seperti ditunjukkan pada Tampilan proses compiling dan uploading, seperti Tabel 1. ditunjukkan pada Gambar 13.

Tabel 1 Penetapan alamat pada jalur input dan output

\begin{tabular}{clcc}
\hline & Alamat di port masukan & \multicolumn{2}{c}{$\begin{array}{c}\text { Alamat di port } \\
\text { keluaran }\end{array}$} \\
\hline PLC & \multicolumn{1}{c}{ Komponen } & PLC & $\begin{array}{c}\text { Kom- } \\
\text { ponen }\end{array}$ \\
\hline I0.00 & Selector Switch "manual" & $\mathrm{Q} 100.00$ & $\mathrm{R} 1$ \\
$\mathrm{I} 0.01$ & Push Button ON & $\mathrm{Q} 100.01$ & $\mathrm{R} 2$ \\
$\mathrm{I} 0.02$ & Push Button OFF & $\mathrm{Q} 100.02$ & $\mathrm{R} 3$ \\
$\mathrm{I} 0.03$ & Selector Switch "otomatis" & $\mathrm{Q} 100.03$ & $\mathrm{R} 4$ \\
$\mathrm{I} 0.04$ & Sensor Fiber Optic "merah" & $\mathrm{Q} 100.04$ & $\mathrm{R} 5$ \\
$\mathrm{I} 0.06$ & Sensor Fiber Optic "hijau" & & \\
$\mathrm{I} 0.08$ & Sensor Photoelectric "tutup botol" & & \\
$\mathrm{I} 0.11$ & Push Button "manual merah" & & \\
$\mathrm{I} 1.00$ & Push Button "manual hijau" & & \\
$\mathrm{I} 1.01$ & Push Button "manual tutup" & & \\
$\mathrm{I} 1.02$ & Push Button "manual cap" & & \\
$\mathrm{I} 1.03$ & Push Button "manual gate" & & \\
$\mathrm{I} 1.04$ & Push Button Emergency Stop & & \\
\hline
\end{tabular}

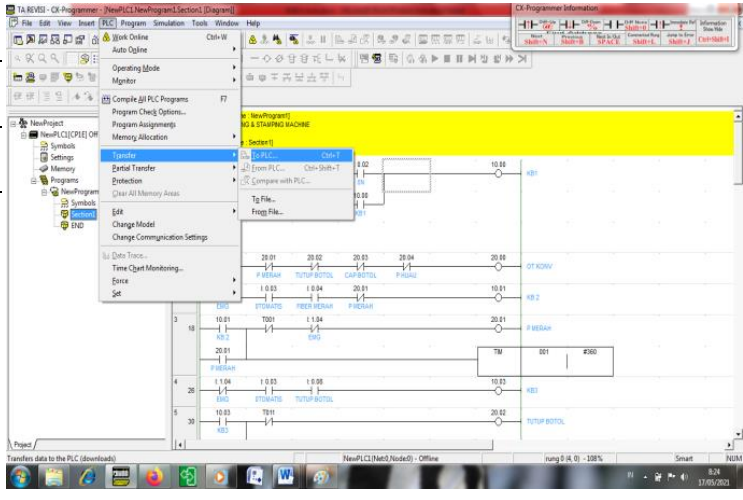

Gambar 13. Tampilan proses compiling dan uploading program ladder dari $P C$ kedalam $P L C$

Berdasarkan Gambar 13 ditunjukkan, bahwa proses

Setelah penetapan pengalamatan pada port compiling dan uploading dilakukan dalam 3 tahapan, masukan/keluaran, maka dilanjutkan dengan penetapan algoritma pemrograman. Tahapan-tahapan pada

DOI: https://doi.org/10.29207/resti.v5i4.3189

Lisensi: Creative Commons Attribution 4.0 International (CC BY 4.0) 
yaitu online to PLC, compile the program, dan transfer to $P L C$.

3.3. Kinerja Simulator Proses Pengisian Air ke Dalam Botol dan Pemasangan Tutup Botol

Pengukuran kinerja berdasarkan pengamatan terhadap 3 (tiga) kondisi, yaitu a) saat sinkronisasi antara simulator proses dan sistem kontrol berbasis $P L C$ dan b) saat pengamatan terhadap pembacaan sensor terpasang dan pengukuran waktu proses pengisian dan pemasangan tutup botol berbantuan sistem pneumatic berbentuk silinder.

3.3.1. Sinkronisasi antara simulator proses dan sistem kontrol berbasis $P L C$

Simulator proses pengisian air minuman ke dalam botol dan pemberian tutup botol terkontrol $P L C$, berdasarkan pedoman konsepsi awal, bahwa simulator dioperasikan dengan dua mode, yaitu manual atau automatic. Mode manual digunakan untuk kemudahan operator saat perawatan, pengecekan, dan penanganan saat terjadi error step. Saat mode manual diaktifkan, setiap aktuator yang terdapat pada mesin simulator dapat dioperasikan manual tanpa melalaui mekanisme sensor detect on. Saat beroperasi mode automatic, maka program tertanam di dalam PLC beroperasi. Berpedoman kepada hal tersebut, maka sinyal masukan dari panel pengoperasian atau masukan oleh sensor diproses sesuai program pada $P L C$ untuk dihasilkan keluaran pengontrolan yang sesuai dan tepat.

Keterhubungan saat sinkronisasi dengan mode manual maupun automatic terhadap sistem pengontrol untuk miniatur mesin konveyor, seperti ditunjukkan pada Gambar 14.

Berdasarkan Gambar 14 dapat dijelaskan, bahwa pPemasangan sejumlah tombol tekan (push botton) pada panel pengoperasian sebagai pen-trigger untuk aktuator guna pengoperasian secara manual terhadap motor $d c$, pompa pengisian, dan silinder pneumatic, sedangkan pemasangan dua jenis sensor (fiberoptic dan photoelectric) berdasarkan deteksi terhadap jenis warna sebagai pen-trigger untuk aktuator guna pengoperasian secara automatic terhadap pompa pengisian, dan silinder pneumatic.

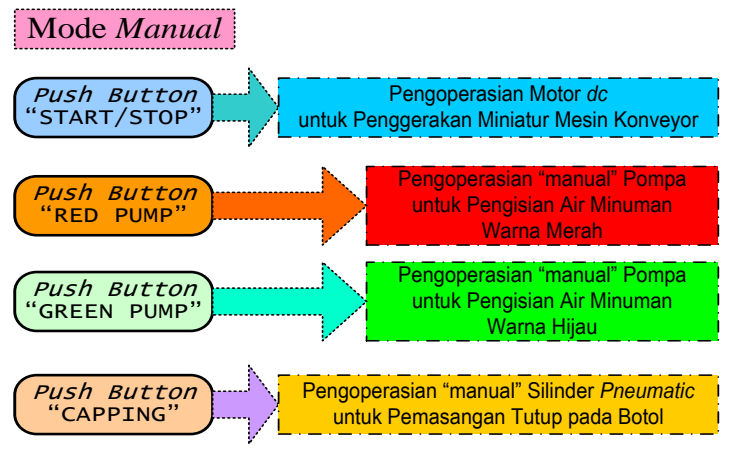

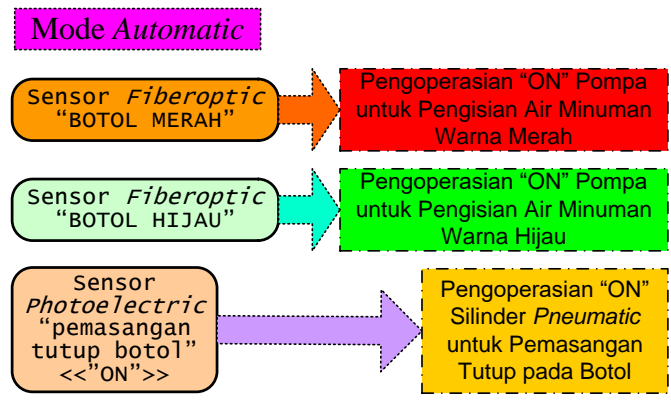

Gambar 14. Keterhubungan saat sinkronisasi dengan mode manual maupun automatic terhadap sistem pengontrol untuk miniatur mesin konveyor

3.3.2. Pembacaan sensor terpasang dan pengukuran waktu proses

Pengamatan proses pengisian air minuman ke dalam botol dan pemasangan tutup pada botol merupakan bentuk pengukuran kinerja terhadap sistem tertanam terpabrikasi. Tampilan hasil pengamatan proses terhadap botol warna merah, seperti ditunjukkan pada Gambar 15.

Berdasarkan Gambar 15 dapat dijelaskan, bahwa pengamatan terhadap botol warna merah, meliputi pendeteksian, proses pengisian air minuman ke dalam botol, dan pemasangan/pemberian tutup untuk botol, sesuai dengan pemrograman.

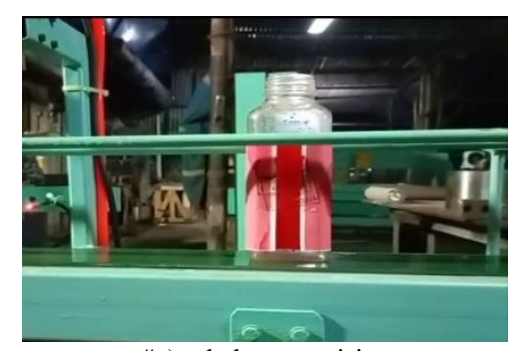

\#a) sebelum pengisian

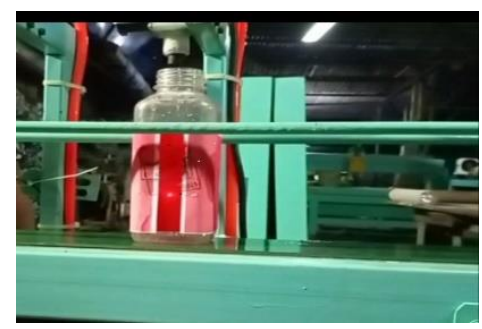

\#b) proses pengisian

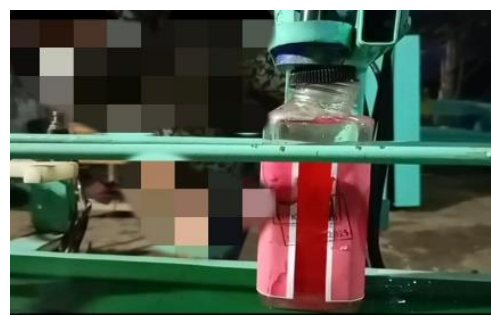

\#c) proses pemberian/pemasangan tutup

Gambar 15. Tampilan hasil pengamatan proses terhadap botol warna merah

DOI: https://doi.org/10.29207/resti.v5i4.3189

Lisensi: Creative Commons Attribution 4.0 International (CC BY 4.0) 
Tampilan hasil pengamatan proses terhadap botol warna sebesar 75\%, berasal dari 4 kali uji coba, 3 kali berhasil hijau, seperti ditunjukkan pada Gambar 16.

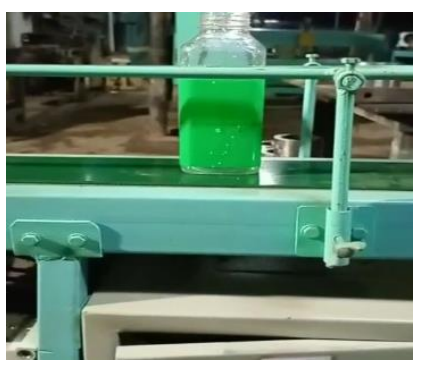

\#a) sebelum pengisian

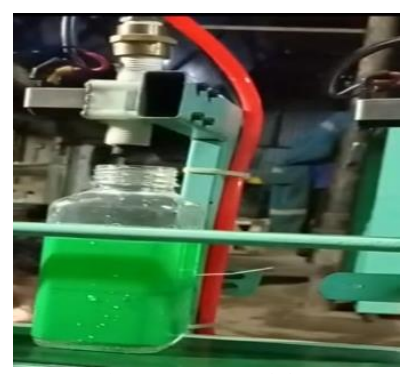

\#b) proses pengisian

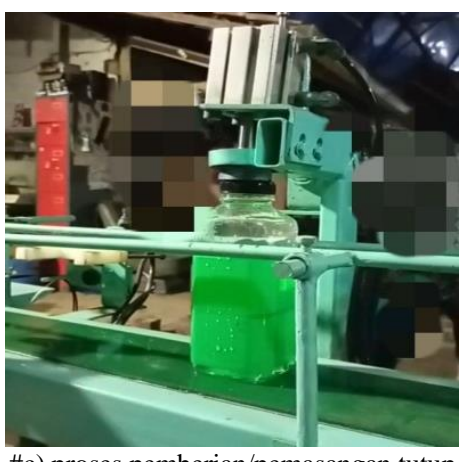

\#c) proses pemberian/pemasangan tutup

Gambar 16. Tampilan hasil pengamatan proses terhadap botol warna hijau

Berdasarkan Gambar 16 dapat dijelaskan, bahwa pengamatan terhadap botol warna hijau juga meliputi pendeteksian, proses pengisian air minuman ke dalam botol, dan pemasangan/pemberian tutup untuk botol, sesuai dengan pemrograman. Pengamatan sensor terpasang dan pengukuran waktu proses pengisian air minuman ke dalam botol dan penutupan tutup pada botol, seperti ditunjukkan pada Tabel 2 .

Tabel 2. Pengamatan sensor terpasang dan pengukuran waktu proses pengisian air minuman ke dalam botol dan penutupan tutup pada botol

\begin{tabular}{|c|c|c|c|c|}
\hline No. & $\begin{array}{c}\text { Percobaan } \\
\text { Otomatis }\end{array}$ & $\begin{array}{c}\text { Waktu } \\
\text { Terprogram }\end{array}$ & Volume & $\begin{array}{l}\text { Pemberian } \\
\text { Tutup }\end{array}$ \\
\hline 1 & $\begin{array}{c}\text { Botol } \\
\text { Merah }\end{array}$ & 55 detik & $470 \mathrm{ml}$ & Gagal \\
\hline 2 & Botol Hijau & 45 detik & $530 \mathrm{ml}$ & Berhasil \\
\hline 3 & $\begin{array}{l}\text { Botol } \\
\text { Merah }\end{array}$ & 55 detik & $530 \mathrm{ml}$ & Berhasil \\
\hline 4 & Botol Hijau & 45 detik & $520 \mathrm{ml}$ & Berhasil \\
\hline
\end{tabular}
dan 1 kali gagal.

\section{Kesimpulan dan Rekomendasi}

Berdasarkan hasil dan bahasan, maka dapat disimpulkan sesuai tujuan penelitian. Bentuk fisis miniatur mesin konveyor dengan belt berbahan PVC green dengan ukuran $200 \mathrm{~cm}$ x $10 \mathrm{~cm}$, roll conveyor berukuran panjang $15 \mathrm{~cm}$ dengan diameter $5 \mathrm{~cm}$ yang dilengkapi dengan shaft coupling yang berfungsi untuk sambungan ke as motor. Pemasangan guide berfungsi untuk pengaman, agar botol tidak terjatuh pada saat conveyor dioperasikan, Penempatan sensor photoelectric merek Sunik E3F-DS30C4 dengan jarak deteksi objek 5-30 cm melalui infrared LED $(660 \mathrm{~nm})$ dengan respon frekuensi sebesar 300 hertz dan response time 1,5 ms (maksimum), sedangkan sensor RGB fiberoptic merek Autonic BF4R dan Autonic $B F 4 G$ dengan respon frekuensi maksimum sebesar 0,5 ms (frequency 1 untuk sensor warna merah) dan 0,7 ms (frekuensi-2 untuk sensor warna hijau). Pemasangan pneumatic cylinder dan pompa pengisian air, meliputi (i) pneumatic cylinder merek Festo dengan panjang stroke $40 \mathrm{~mm}$ dengan diameter $16 \mathrm{~mm}$, digunakan sebagai penekan tutup botol, dan pneumatic cylinder merek Airtac berdiameter $8 \mathrm{~mm}$ dengan panjang stroke $50 \mathrm{~mm}$, digunakan sebagai pendorong tutup botol, dengan tekanan maksimum 3 bar. Panel operasi dan pengawatan (wiring), meliputi (i) modul PLC Omron CP1E-E30-SDRA, (ii) switched mode power supply $24 \mathrm{Vdc} 4 \mathrm{~A}$;; (iii) $M C B 6 \mathrm{~A}$., (iv) sejumlah relai dengan tegangan koil $24 \mathrm{Vdc}$; (v) tombol emergency stop; (vi) tombol push button, dan (vii) selector switch.

Pemrograman berbasis aplikasi $C X$-progammer untuk sistem PLC sebagai sistem pengontrol, dilakukan dengan sejumlah tahapan. Penyediaan aplikasi $C X$ programmaer melalui pengunduhan dan pemasangan pada komputer personal, berupa (i) proses penyalinan aplikasi pada komputer, dan (ii) proses pemasangan beberapa tahapan. Penentuan algoritma dan penyusunan struktur ladder, diakhiri dengan proses compiling dan uploading dari PC ke dalam PLC berbantuan kabel USB.

Ketepatan proses pengisian dan pemasangan tutup botol, didasarkan kepada pembacaan pulse dari photoelectric sensor dan fiberoptic sensor. Sistem pengisian air beroperasi secara otomatis pada saat fiberoptic sensor deteksi keberaadan botol, sehingga konveyor berhenti dan proses pengisian air berlangsung. Proses penutupan botol secara otomatis berfungsi, apabila photoelectric sensor deteksi botol, sehingga konveyor berhenti dan sistem pemasang tutup dan penekan tutup beroperasi. Setelah proses penutupan botol selesai, konveyor beroperasi kembali. Tekanan udara pada pneumatic unit berpengaruh terhadap proses penutupan botol.

Berdasarkan Tabel 2 dapat dijelaskan, bahwa kinerja Rekomendasi terhadap penelitian ini dapat disampaikan, simulator terpabrikasi ini berupa tingkat keberhasilan bahwa hasil penelitian ini dapat digabungkan dengan

DOI: https://doi.org/10.29207/resti.v5i4.3189

Lisensi: Creative Commons Attribution 4.0 International (CC BY 4.0) 
proses sebelum pengisian air minuman dan pemasangan tutup botol maupun proses setelahnya, seperti pemberian label dan pengepakan (packing) produksi atau lainnya, sehingga dapat menjadi sebuah hasil penelitian yang terintegrasi.

\section{Daftar Rujukan}

[1] I. Chaerunnisa, S.B. Mulia, dan M. Eriyadi, (2018, Juli). Aplikasi PLC pada Alat Pengisian Air Minum Otomatis. Jurnal Elektra. [Online]. 3(2), 61-68. Tersedia di: https://pei.ejournal.id/jea/article/view/56/49.

[2] F. Vanderweyst, "Beverage Filling System," Canada Patent CA2510251A1, Jun. 20, 2005.

[3] L.A. Bryan and E.A. Bryan. "Introduction to Programmable Controllers," in Programmable Controllers: Theory and Implementation, $2^{\text {nd }}$ ed., Atlanta, GA: An Industrial Text Company Publication, 1997, pp. 4-32.

[4] E.A. Parr. "Computers and Industrial Control," in Industrial Control Handbook, $3^{\text {rd }}$ ed. New York, NY: Industrial Press, Inc., 1999, p. 438.

[5] E.A. Parr. "Programmable Controllers," in Electrical Engineer's Reference Handbook, Sixteenth Edition (Editors: M.A. Loughton and D.F. Warne). Burlington, MA: Newnes, 2003, pp. 16/3$16 / 52$.

[6] D.E. Kandray. "Introduction to Programmable Logic Controllers," in Programmable Automation Technologies: An Introduction to CNC, Robotics, and PLCs. New York, NY: Industrial Press, Inc., 2010.pp. 1-29.

[7] NEMA (the National Electrical Manufacturers Association). 2013. NEMA ICS 61131-1-2005 (R2013). [Online] Available: https://www.nema.org/Standards/ComplimentaryDocuments/IC S\%2061131\%201-2005(R2013)-contents-and-scope.pdf

[8] W. Bolton. Programmable Logic Controllers, $6^{\text {th }}$ ed. Burlington, MA: Newnes, 2015, pp. 1-19.

[9] D. Patel. Introduction Practical PLC (Programmable Logic Controller) Programming. Munich, Grin Verlag, 2017. [Online]. Available: https://www,grin.com/document/413360.

[10] OMRON, The CP1E Programmable Controller: Economical, Easy to Use, and Efficient, Tokyo, Japan, 2013, pp. 1-48.

[11] F.G. Airlangga, A. Triwiyatno, dan Sumardi. (2017, Maret). Perancangan Sistem Automasi pada Pengemasan Susu Dalam Botol dengan Programmable Logic Controller (PLC) Omron CP1E terhadap Purwarupa Filling Bottle and Capping Machine. Transient. [Online]. 6(1), 103-109. Tersedia di: https://ejournal3.undip.ac.id/index.php/transient/article/view/17 069.

[12] M. Wildan, A. Goeritno, dan J. Irawan. "Embedded Device Berbasis PLC pada Miniatur Konveyor untuk Pengoperasian Simulator Rejection System," Jurnal RESTI (Rekayasa Sistem dan Teknologi Informasi), vol. 5, no. 2, hlm. 301-311, April 2021. https://doi.org/10.29207/resti.v5i2.2994

[13] Mitsubishi Electric, 1999. FX Series Programmable Controllers: Programming Manual. [Online] (Updated November 1999). Available:

http://dl.mitsubishielectric.com/dl/fa/document/manual/plc_fx/jy 992d48301/jy992d48301j.pdf. [Accessed 30 January 2018].

[14] S.Y. Dimpudus, V.C. Poekoel, and P.D.K. Manembu. (2015), "Sistem Pengepakan Botol Minuman Kemasan Berbasis Programmable Logic Controller," E-Journal Teknik Elektro dan Komputer. [Online]. 4(7), 65-72. Tersedia di: https://ejournal.unsrat.ac.id/index.php/elekdankom/article/view/ $10717 / 10305$.

[15] A. Goeritno, dan S. Pratama, "Rancang-Bangun Prototipe Sistem Kontrol Berbasis Programmable Logic Controller untuk Pengoperasian Miniatur Penyortiran Material," Jurnal Rekayasa Elektrika, vol. 16, no. 3, hlm. 198-206, Desember 2020. http://dx.doi.org/10.17529/jre.v16i3.14905

[16] S. Tirta, dan A. Goeritno, "Simulator Berbasis PLC untuk Pengaturan Lalu-lintas Jalan Raya pada Perlintasan Jalur Kapal," Jurnal RESTI (Rekayasa Sistem dan Teknologi Informasi), vol. 4, no. 6, hlm. 1007-1016, Desember 2020. https://doi.org/10.29207/resti.v4i6.2668

[17] R. Pawar, and N.R. Bhasme. (2016, June). Application of PLC's for Automation of Processes in Industries. Int. Journal of Engineering Research and Applications (IJERA). [Online]. 6(6). 53-59. https://www.ijera.com/papers/Vol6_issue6/Part\%20\%203/I0606035359.pdf

[18] R. Langmann, and M. Stiller. (2019, September). The PLC as a Smart Service in Industry 4.0 Production Systems. Applied Science. [Online]. 9(3815), 1-22. Available: https://www.mdpi.com/2076-3417/9/18/3815/htm.

19] H. Carlsson, B. Svensson, F. Danielsson, and B. Lennartson, "Methods for Reliable Simulation-Based PLC Code Verification," in IEEE Transactions on Industrial Informatics, vol. 8, no. 2, pp. 267-278, May 2012, doi: 10.1109/TII.2011.2182653.

[20] E.R. Alphonsus and M.O. Abdullah, "A review on the applications of programmable logic controllers (PLCs)," Renewable and Sustainable Energy Reviews, 60 (C), July 2016, pp. 1185-1205. https://doi.org/10.1016/j.rser.2016.01.025.

[21] M.S. Saleh, K.G. Mohammed, Z.S. Al-sagar, and A.Z. Sameen. "Design and Implementation of PLC-Based Monitoring and Sequence Controller System," Journal of Advanced Research in Dynamical and Control Systems, vol 10, no. 02 special issue, 2018, pp. 2281-2289.

[22] A. Goeritno, dan Y. Herutama, "Sistem Elektronis Berbantuan PC untuk Pemantauan Kondisi Pasokan Daya Listrik," Jurnal Rekayasa Elektrika, vol. 14, no. 2, hlm. 96-104, Agustus 2018. http://dx.doi.org/10.17529/jre.v14i2.10904

[23] G. Gridling, and B. Weiss. Introduction to Microcontrollers, Courses 182.064 \& 182.074, Embedded Computing Systems Group, Institute of Computer Engineering, Vienna University of Technology, Version 1.4 (2007 Feb. 26), pp. 11-88

24] Atmel. 8-bit AVR Microcontroller with 32KBytes In-System Programmable Flash. San Jose, CA: Atmel Corporation, 2011. http://www.atmel.com/Images/doc2503.pdf

[25] M. Banzi, Getting Started with Arduino: the Open Source Electronics Prototyping Platform, $2^{\text {nd }}$ ed. Sebastopol, CA: O'Reilly Media, 2011, pp. 17-24.

[26] M. Margolis, Getting Started: Arduino Cookbook, $2^{\text {nd }}$ ed. Sebastopol, CA: O'Reilly Media, Inc., 2011, pp. 1-21.

[27] S.F. Barret, Arduino Microcontroller Processing for Everyone! $3^{\text {rd }}$ ed. San Rafael, CA: Morgan \& Claypool, 2013, pp.1-31. https://doi.org/10.2200/S00522ED1V01Y201307DCS043

[28] Atmel, 8-bit AVR Microcontroller ATmega32A Datasheet. San Jose, CA: ATMEL Corporation, 2014. http://ww1.microchip.com/downloads/en/DeviceDoc/Atmel2549-8-bit-AVR-Microcontroller-ATmega640-1280-12812560-2561_datasheet.pdf.

[29] M. Banzi, and M. Shiloh, Getting Started with Arduino: the Open Source Electronics Prototyping Platform, $3^{\text {rd }}$ ed. Sebastopol, CA: Maker Media, 2015, pp. 15-22. 